\title{
Study on the effect of the oceanic water layer on strong ground motion simulations
}

\author{
Anatoly Petukhin ${ }^{1}$, Tomotaka Iwata ${ }^{2}$, and Takao Kagawa ${ }^{3}$ \\ ${ }^{1}$ Geo-Research Institute, Itachibori 4-3-2, Nishi, Osaka 550-0012, Japan \\ ${ }^{2}$ Disaster Prevention Research Institute, Kyoto University, Japan \\ ${ }^{3}$ Tottori University, Japan
}

(Received November 27, 2007; Revised June 30, 2010; Accepted July 23, 2010; Online published October 28, 2010)

\begin{abstract}
We studied the effect of the oceanic water layer on strong ground motion simulations. Source faults of subduction zone earthquakes, such as the Nankai-Tonankai earthquake, West Japan, are situated in the offshore area, under a thick water layer. The necessity of including the oceanic water layer in the velocity model for simulations employing the finite difference method is debated by many researchers, and consideration given to the possibility of neglecting by this layer, which would reduce the computation time and stabilize the calculations. Although the oceanic water layer has a low velocity and density, it can affect surface wave generation. In this study, for demonstration purposes, we calculated and compared strong ground motions from three source fault models, placed into the boundary between the crust and subducting plate, where source rupture of the Tonankai earthquake is expected. Simulations were made for two realistic three-dimensional velocity models: without and with the oceanic water layer. The model without the oceanic water layer was constructed simply by subtracting the depth of the oceanic layer from the depth of all velocity interfaces under the ocean. This procedure keeps the thickness of the layers (oceanic sediments, surface low-velocity layer, upper crust, and lower crust) the same as in the model with the oceanic layer and reduces simulation errors. Simulations were made for the set of sites on a line across the subduction zone and directed to the Osaka basin. The results show that the water layer has a strong effect on the fundamental mode of the Rayleigh wave, which can be generated by the shallow (approx. $5 \mathrm{~km}$ ) source. Considering that all asperities of the expected Nankai-Tonankai earthquake are deep $(>10 \mathrm{~km})$, we conclude that the effect of the water layer can be neglected for ground motions at land sites.
\end{abstract}

Key words: Nankai-Tonankai earthquake, strong ground motion simulations, crustal velocity, finite difference method.

\section{Introduction}

Ground motion simulations and predictions based on the source model and the underground velocity structure model are quite important for understanding strong ground motion characteristics and related earthquake disasters. Since the 1994 Northridge, USA, and the 1995 Kobe, Japan, earthquakes, strong motion simulations using the heterogeneous source and realistic three-dimensional (3-D) underground velocity structure models have become successful and quite popular in the research field of applied seismology and earthquake engineering.

The effect of the water layer is rarely considered in the numerical simulations of strong ground motions. Firstly, in terms of finite difference simulations, researchers consider that the introduction of the low-velocity $\left(V_{P}=1500 \mathrm{~m} / \mathrm{s}\right)$ water layer into the velocity model would decrease the maximum grid size and time step and increase the computation time and number of time steps, ultimately causing numerical instabilities. Secondly, the commonly assumed viewpoint is that the effect of the water layer on the generation of

Copyright (C) The Society of Geomagnetism and Earth, Planetary and Space Sciences (SGEPSS); The Seismological Society of Japan; The Volcanological Society of Japan; The Geodetic Society of Japan; The Japanese Society for Planetary Sciences; TERRAPUB.

doi:10.5047/eps.2010.07.014 the direct waves is small due to its low velocity and density. In contrast, using boundary element method estimations for simple 2-D models, Hatayama (2004) demonstrated that effect of the shallow water layer on the generation of Rayleigh waves could be strong. The effect of low-frequency or longperiod basin-induced surface wave generation in metropolitan areas on such structures as skyscrapers, large bridges, and oil tanks has recently attracted increased interest, focusing attention once again on the problem of the effect of the water layer on surface wave generation.

The target area of this study is the Kinki in Western Japan and adjacent areas (see Fig. 1). Many large cities are located in this area, including Osaka, Kobe, Kyoto, and Nagoya. The Kinki area has a high seismic hazard potential rating. Based on the long-term evaluation of earthquake occurrence, the Headquarters for Earthquake Research Promotion (HERP) of the Ministry of Education, Culture, Sports, Science, and Technology (MEXT), Japan, reported that the occurrence potentials of the next Nankai (off Shikoku) and Tonankai (off Kii Peninsula) earthquakes are high: about 60-70\% within the next 30 years starting from 2009 (HERP, 2009). The source regions of these earthquakes, and of those of other subduction zone earthquakes, are mostly located in the offshore area, under an oceanic water layer of 1-3 km depth (Fig. 1). 


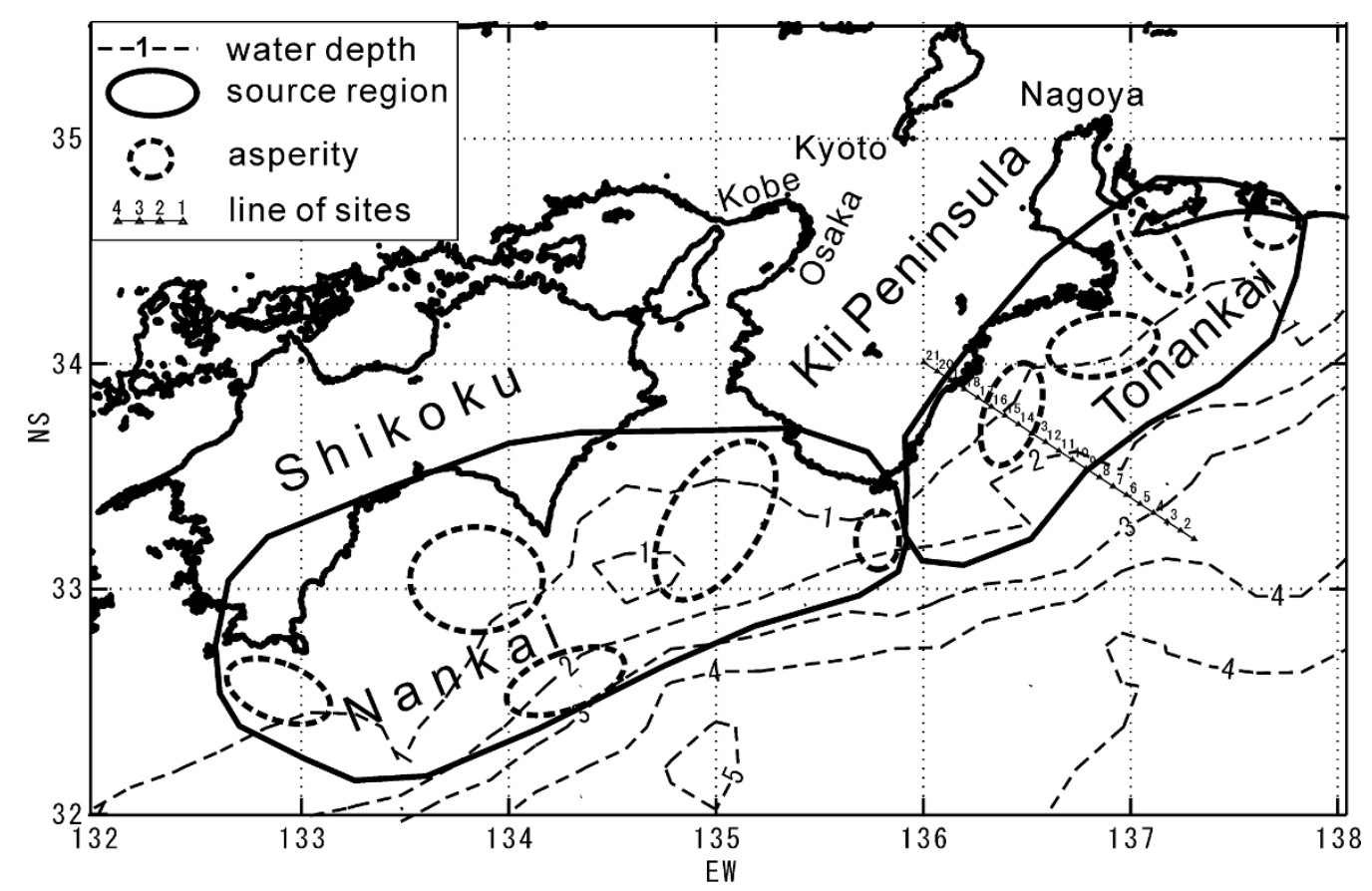

Fig. 1. Map of target region. Source regions of the $M$ 8-class Nankai and Tonankai earthquakes are overlapped with the depth contours of the oceanic water layer. Numbered line shows the linear site array that was used for the simulations in this study. Source regions and asperities of the Nankai and Tonankai earthquakes are simplified from the source model by the Central Disaster Prevention Council of Cabinet Office (see, for example, Tsurugi et al., 2005). Osaka, Kobe, Kyoto and Nagoya cities located in the disaster area are also shown for reference.

Studies of the effect of the oceanic water layer on the propagation of seismic waves from local and regional earthquakes are scarce. Nagano and Motosaka (1994) simulated seismic wave propagation by the hyper-element method using a velocity structure model with a water layer overlying the ground and reported that the water layer can influence seismic motion. In order to study the effect of the water layer, Hatayama (2004) applied the boundary element method in a shallow bay model. Three types of models were examined: (1) with a water layer; (2) without a water layer, where the water layer was replaced by surface sediments; (3) without a water layer, where the water layer is replaced by a vacuum (this procedure retains the same thickness of the surface sediment layer as in the first model). Hatayama (2004) found that the Rayleigh waves are strongly influenced by the water layer and that the deeper the water layer, the longer the period of ground motions influenced. The substitution of sediments for water (model 2) had a bad effect. At a land station in Hokkaido, Nakanishi (1992) observed Rayleigh waves guided by the oceanic trench (Kurile trench). His simulations show that this could have been due to the effect of the deep water layer over the trench.

The aim of the study reported here was to test the effect of the water layer on ground motions within the constraints of a realistic 3-D velocity model with a deep oceanic layer. To this end, we made finite difference simulations for several point sources located in the source region of the Tonankai earthquake, off Kii Peninsula. We limited our study to the generation of surface waves in oceanic sedimentary layers. For this reason, calculations were made for a line of sites across the subduction zone, in the Osaka direction, which only slightly "runs up" into the inland area (see Fig. 1). We developed two velocity models: (1) with and (2) without a deep oceanic water layer. Following the recommendations of Hatayama (2004), the velocity model without the oceanic water layer was constructed in such a way that the thickness of other velocity layers was preserved (Iwata et al., 2008).

\section{3-D Velocity Model}

Many velocity structure models have been designed by different organizations and research groups. Most of these were designed for evaluating ground shaking level related to the earthquake disaster of general houses or for seismic intensity mapping. However, our target is the simulation of long-period ground motion. Iwata et al. (2008) constructed the crustal velocity structure model for the Kinki area by compiling many of the seismic survey results available at the time. Here, we briefly describe this velocity model, concentrating on the accretion prism part, which is related our study.

The general principle of crustal velocity modeling is to a build model from several layers with each layer having a constant value of velocity, density, and quality factor $Q$. This traditional approach allows us to directly incorporate the results of many previous studies into the model, such as seismic profiling and receiver function inversion, which employ the same approach with constant velocity layers. Model interfaces between layers are 3-D. They are constructed using the spline interpolation method, following the approach developed earlier for the Osaka basin model (Kagawa et al., 1993, 2004).

In 2004, a deep seismic exploration experiment across the Kinki area was conducted within the framework of the project of regional characterization of the crust in metropolitan areas for the prediction of strong ground motion (Ito et al., 2005). Before this experiment, crustal 


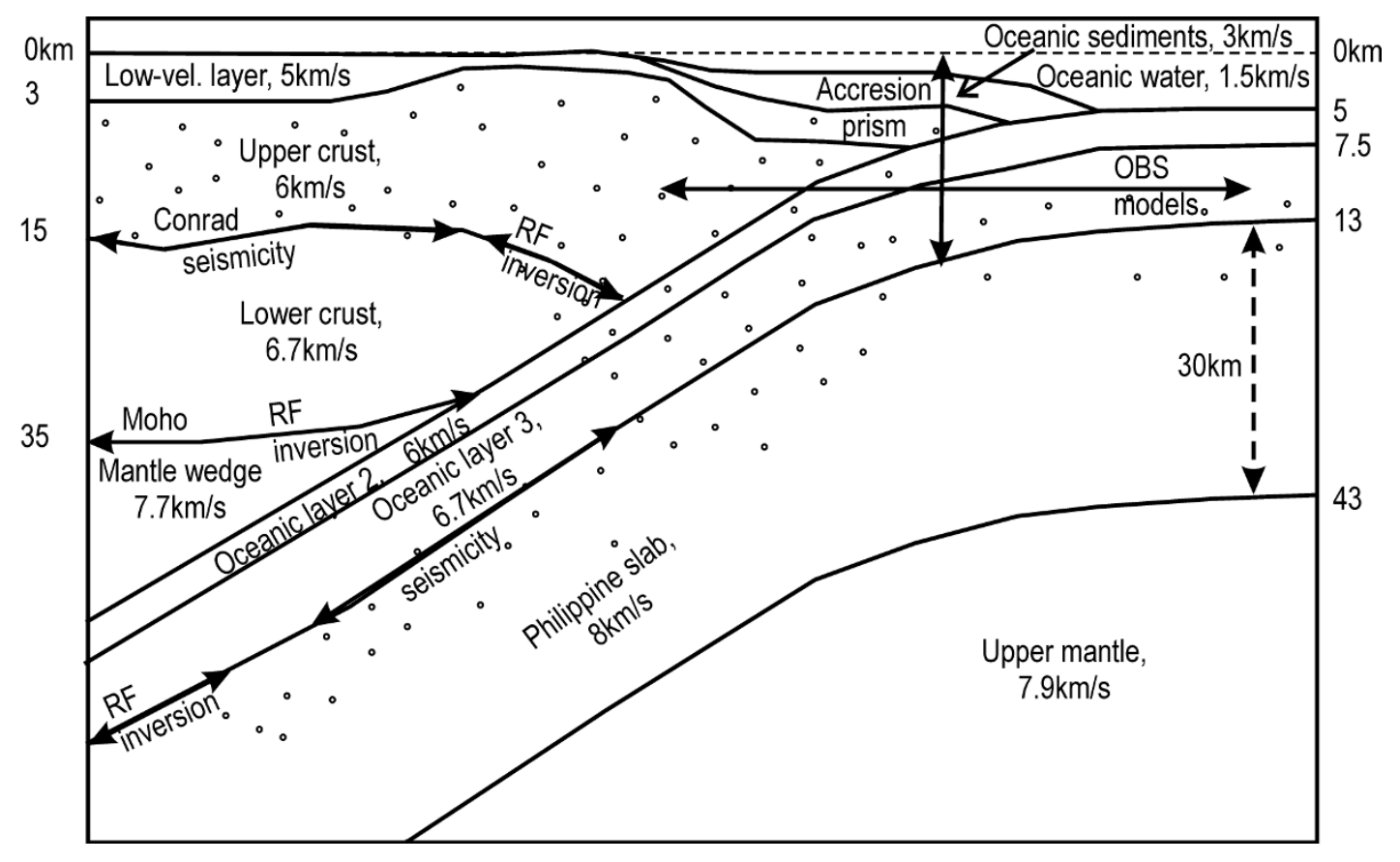

Fig. 2. Schematic illustration of the 3-D velocity model. Double arrows approximately indicate the range of the model with the data used. Open circles indicate the distribution area of micro-earthquakes. Numbers near vertical axes show the approximate depth of the interfaces. Velocities inside layers are the $V_{P}$ values.

velocity structure and subducting slab structure had been studied by $P$-wave exploration surveys (e.g. Nakanishi et al., 1998, 2002a, b; Kodaira et al., 2002) and, using earthquake records, by the receiver function method (e.g. Yamauchi et al., 2003). We also refer to the seismic crosssection databases (ERI, 2006; JAMSTEC, 2006). The velocity structure models from the OBS (Ocean Bottom Seismometer) measurements were used.

In the subducting area, the accretion prism or the sedimentary wedge can be observed in the cross-sections of the exploration surveys (e.g., Nakanishi et al., 1998, 2002a, b; Kodaira et al., 2002). These sediments seem to be several kilometers in thickness and to strongly affect the results of the ground motion simulation for subduction events (e.g., Yamada and Iwata, 2005).

Figure 2 shows a schematic cross-section of the crustal velocity structure model, including the subducting Philippine Sea slab in the Kinki area. It reflects the main principles of 3-D velocity modeling, as developed by Petukhin et al. (2004) and Petukhin and Kagawa (2006), which are: (1) intensive usage of the OBS velocity models in the off-shore areas for the accretion prism and oceanic crust modeling; (2) employing seismicity data for tracing the seismogenic slab and seismogenic upper crust; (3) intensive usage of the receiver function inversion results for tracing the Moho, Conrad and aseismic slab; (4) employing deep seismic profiling results for inland areas wherever possible; (5) employing 1-D velocity models for the hypocenter locations and generalized seismic tomography results for the rest of target area not covered by data.

\subsection{Construction of velocity interfaces}

The velocity model was constructed from ten constant velocity layers: (1) oceanic water layer, (2) oceanic sedimentary layer (accretion prism, OS), (3) surface low- velocity layer (LV), (4) upper crust (UC), (5) lower crust (LC), (6) mantle wedge (MW), (7) subducted oceanic layer 2 (oceanic upper crust, SOC2), (8) subducted oceanic layer 3 (oceanic lower crust, SOC3), (9) slab (oceanic upper mantle), and (10) upper mantle. Their boundaries are next interfaces: (1) ground surface (or ocean bottom), (2) lower interface of the OS layer, (3) lower interface of the LV layer, (4) Conrad interface, (5) Moho interface, (6) top boundary of the SOC2 (oceanic upper crust), (7) top boundary of the SOC3 (oceanic lower crust), (8) upper boundary of the slab (oceanic Moho), and (9) lower boundary of the slab (see Fig. 2).

Ground surface. We assumed that the height of the ground surface is zero in inland areas. For the oceanic bottom, we used the depth values from the OBS velocity models. This methodology provides accurate values for layer thickness. The results can be seen in Fig. 3(a).

Lower interface of the oceanic sedimentary layer. We used OBS seismic profiles data. For oceanic areas that are not covered by the OBS studies, we extrapolated the OBS results and assumed that the thickness of the OS layer is zero. That can be seen in Fig. 3(b).

Lower interface of the low-velocity layer. For inland areas, deep seismic profile results were used wherever possible. In the rest of the target area, the LV layer was assumed to be at a constant depth, namely, $3 \mathrm{~km}$, according to the velocity models used for hypocenter location. For the accretion prism, we used OBS seismic profile data. For oceanic areas not covered by the OBS studies, we extrapolated the OBS results and assumed that the thickness of the LV equals $1 \mathrm{~km}$, as shown in Fig. 3(c).

Conrad interface. Similar to Petukhin et al. (2004), we assumed that the Conrad interface approximately coincides with the lower boundary of the crustal seismicity. The lower 

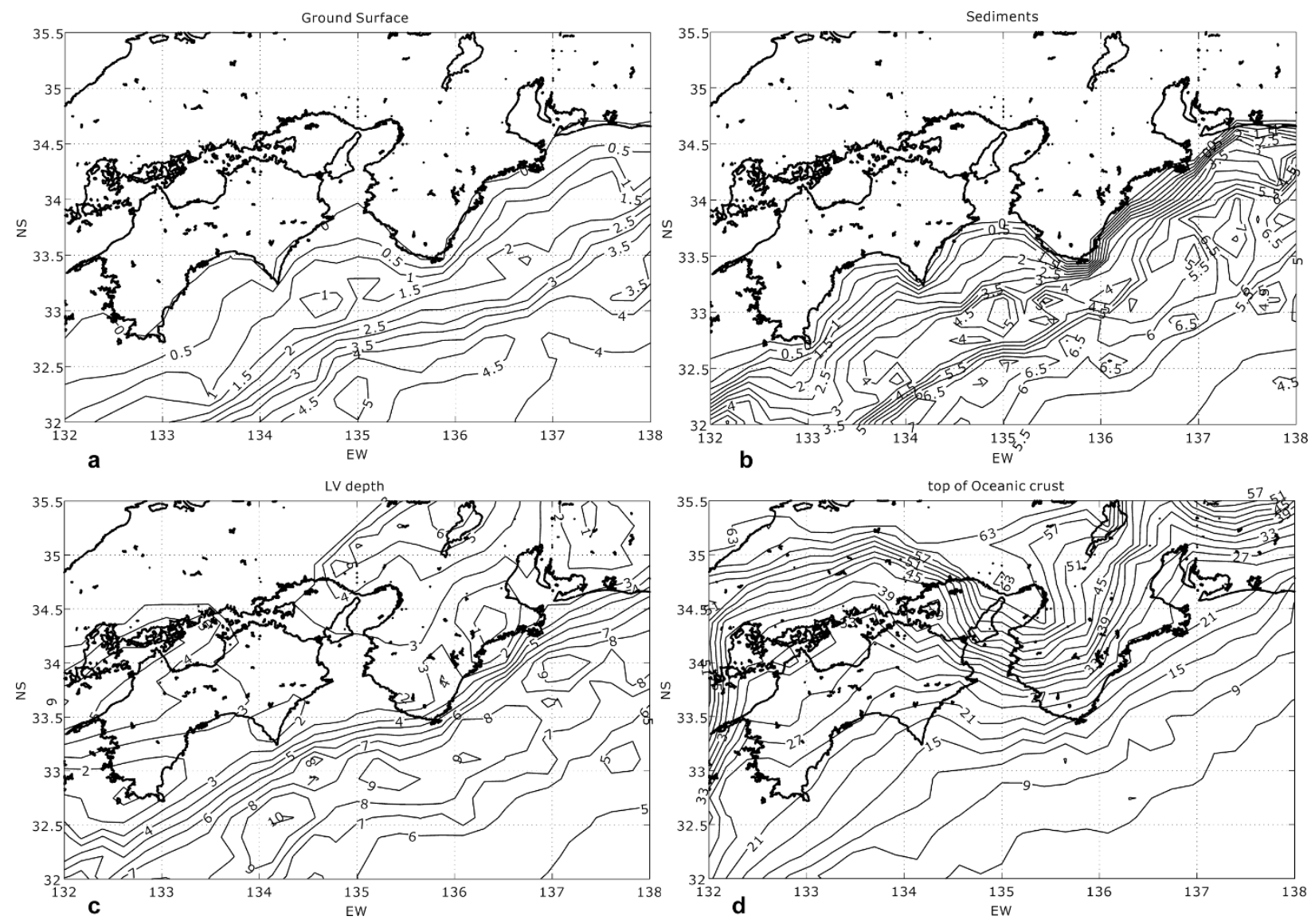

Fig. 3. Depth of four uppermost interfaces of the 3-D velocity model: (a) oceanic water layer (sea bottom), (b) oceanic sediments layer, (c) surface low-velocity layer, and (d) upper interface of the subducted oceanic layer 2. Numbers on contours indicate depth in kilometers.

boundary of the seismicity depth obtained by Ito (2002) was used. For the area where seismicity of the upper crust merges with the seismicity of the slab, we used the receiver function inversion results of Yamauchi et al. (2003).

Moho interface. Two kinds of data can be used to construct the 3-D Moho interface: the receiver function inversion (Yamauchi et al., 2003; Shiomi et al., 2004) and the travel time inversion results (Salah and Zhao, 2004). Both Moho and Conrad interfaces were smoothly combined with the top boundary of the subducted oceanic layer 2 .

Top of the subducted oceanic layer 2. The OBS velocity models were used in the offshore area covered by the OBS reflection profiles. These were then extrapolated to the inland areas, assuming a constant difference (approximately $7-8 \mathrm{~km}$ ) between the depth of the top of the SOC2 and the depth of the upper boundary of the slab (see below). Here, we used the observation that the subducting oceanic crust (i.e., SOC2 and SOC3) is mostly aseismic, whereas all subduction seismicity is concentrated inside the slab, which is also subducting the oceanic upper mantle (see, for example, Ito et al., 2005). The results are shown in Fig. 3(d).

Top of the subducted oceanic layer 3. The SOC3 lies just above the slab. The OBS velocity models were used once again in the offshore area covered by the OBS reflection profiles. For inland areas, we summarized the OBS velocity models and simply assumed that the ratio of the thicknesses of the SOC2 and SOC3 is approximately 1:2.
Upper boundary of slab. We assumed that the slab is a high-velocity layer located below the oceanic Moho that includes most of the deep seismicity area. Therefore, the depth of the upper boundary of slab in the offshore areas was estimated using the OBS models. The depth of the upper boundary of the seismogenic slab in the inland areas was estimated using seismicity data. The depth of the upper boundary of the aseismic slab in the inland areas was estimated using the receiver function inversion results. Between these three areas, the slab surface was smoothly interpolated. Steps of the depth were corrected, if necessary, assuming the following priority: the OBS models (highest), the seismicity data, and the inversion of receiver function (lowest).

We then constructed a velocity model without the oceanic water layer by simply subtracting the depth of the oceanic water layer from the depth of all other velocity interfaces under the ocean. This procedure keeps the thickness of layers (OS, LV, SOC2 and SOC3) the same as in the model with the oceanic water layer and reduces simulation errors. Cross-sections of both models along the site line are shown in Fig. 4.

\subsection{Velocity model parameters}

Because velocity structure models have been mainly obtained for the $P$-waves, we refined them and assigned $S$ wave velocity values for each layer. Table 1 shows the $P$ and $S$-velocity values, density, and $Q$-values assigned to the each layer. These were estimated by generalizing (1) 

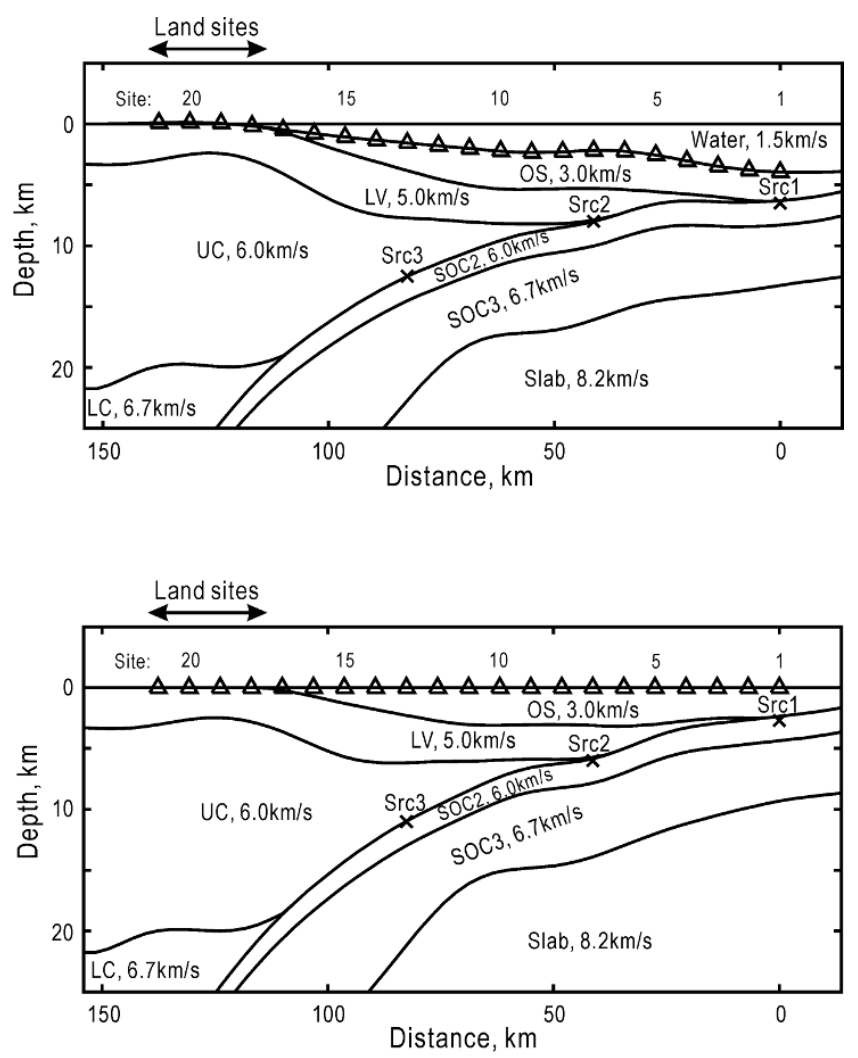

Fig. 4. Cross-sections of 3-D velocity models (along the line of sites, triangles): with water layer (upper) and without water layer (lower). Location of three point sources, Src1, Src2, and Src3, used for simulations are also shown (crosses). See text for the abbreviations of the velocity layers. $P$-wave velocities in each layer are also shown for reference.

Table 1. Parameters of the 3D velocity model.

\begin{tabular}{lcccr}
\hline Layer & $V_{p}, \mathrm{~m} / \mathrm{s}$ & $V_{s}, \mathrm{~m} / \mathrm{s}$ & Density, $\mathrm{kg} / \mathrm{m}^{3}$ & $Q$-value \\
\hline Oceanic water layer & 1500 & 0 & 1000 & 57,822 \\
\hline Oceanic sedimentary layer & 3000 & 1500 & 2250 & 300 \\
Surface low-velocity layer & 5000 & 2700 & 2740 & 500 \\
Upper crust & 6000 & 3450 & 2800 & 1000 \\
Lower crust & 6700 & 3900 & 2900 & 500 \\
Mantle wedge & 7700 & 4450 & 3100 & 1000 \\
Subducted oceanic layer 2 & 6000 & 3450 & 2700 & 500 \\
Subducted oceanic layer 3 & 6700 & 3900 & 2800 & 500 \\
Slab & 8000 & 4630 & 3220 & 1000 \\
Upper mantle & 7900 & 4570 & 3100 & 1000 \\
\hline
\end{tabular}

the 1-D velocity models, used for the hypocenter location in the studied area, (2) the seismic tomography results (e.g., Zhao and Hasegawa, 1993), and (3) the OBS velocity models. $Q$-values for the 3-D velocity model are basically those reported in Iwata et al. (2008), except for the water layer. We introduced a large $Q$-value in the water layer, as recommended in the AK135 global model. $Q$-values are also shown in Table 1. We used the FDM calculation with inelastic effect given by Graves (1996).

\section{Finite Difference Simulations}

We calculated and compared strong ground motions from three sources, Src1, Src2, and Src3, placed into the boundary between crust and subducting plate, where source rupture of the Tonankai earthquake is expected (see Fig. 4). Strike and rake angles of source mechanisms are the same for all three sources. We used the values of strike 215, rake 90 in accordance with Tsurugi et al. (2005); these values are based on the expected source model of the Tonankai Earthquake proposed by the Central Disaster Prevention Council of Cabinet Office. The dip angle was adjusted to the subducting plate local interface gradient, which is approximately $14^{\circ}$ for the deeper events (Src2 and Src3); this value is in agreement with the expected source model of the Tonankai Earthquake. For the shallower event (Src1), the local interface spatial gradient is almost zero, and we assumed that the fault plane is horizontal. Double couple source is an equivalent force system of a dislocation in a 'homogeneous medium', and for this reason we put sources two grids above (not just on) the interface between the crust and subducted plate.

Simulations were made for the two 3 -D velocity models 
(a)

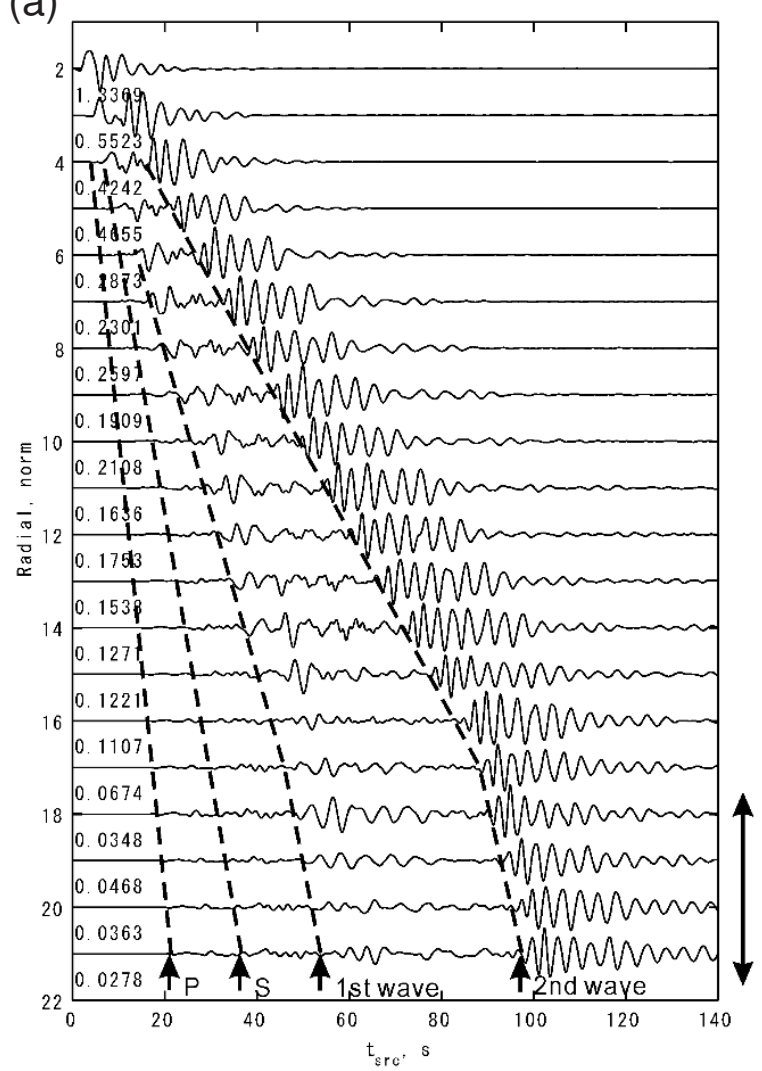

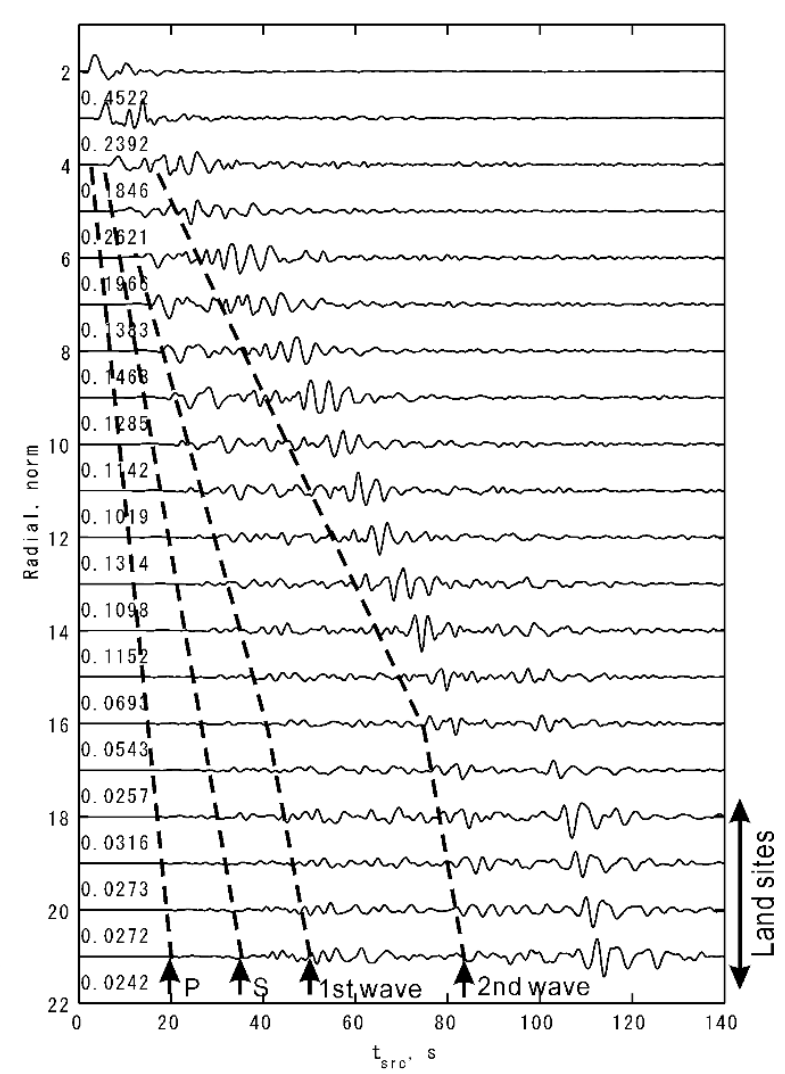

(b)

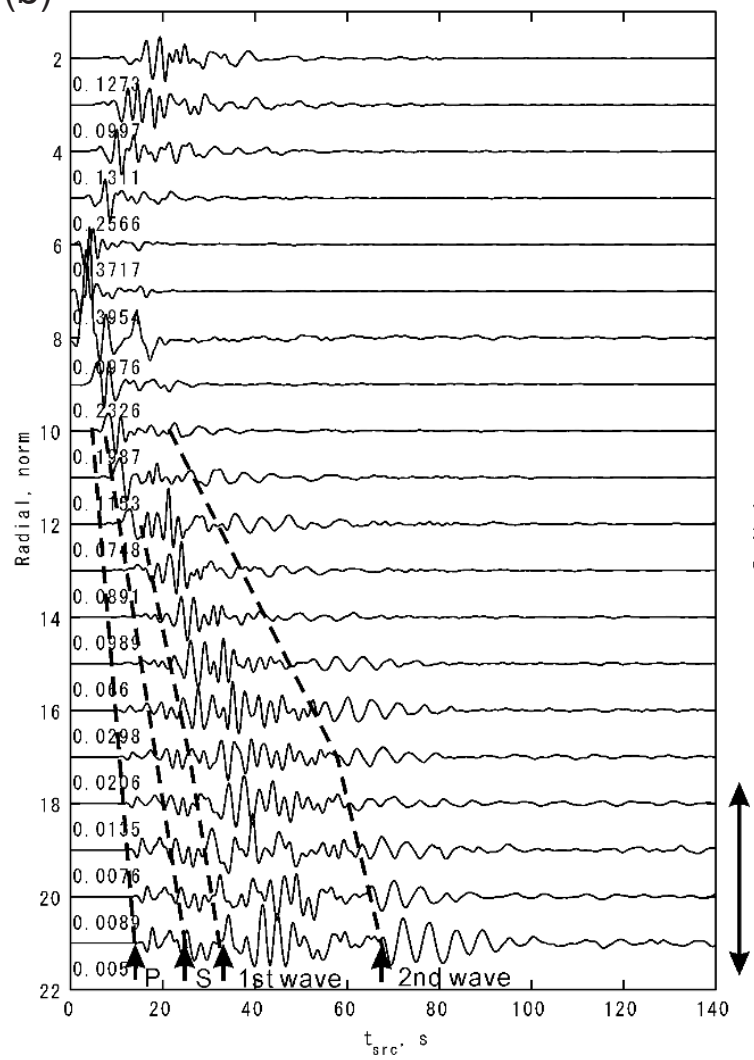

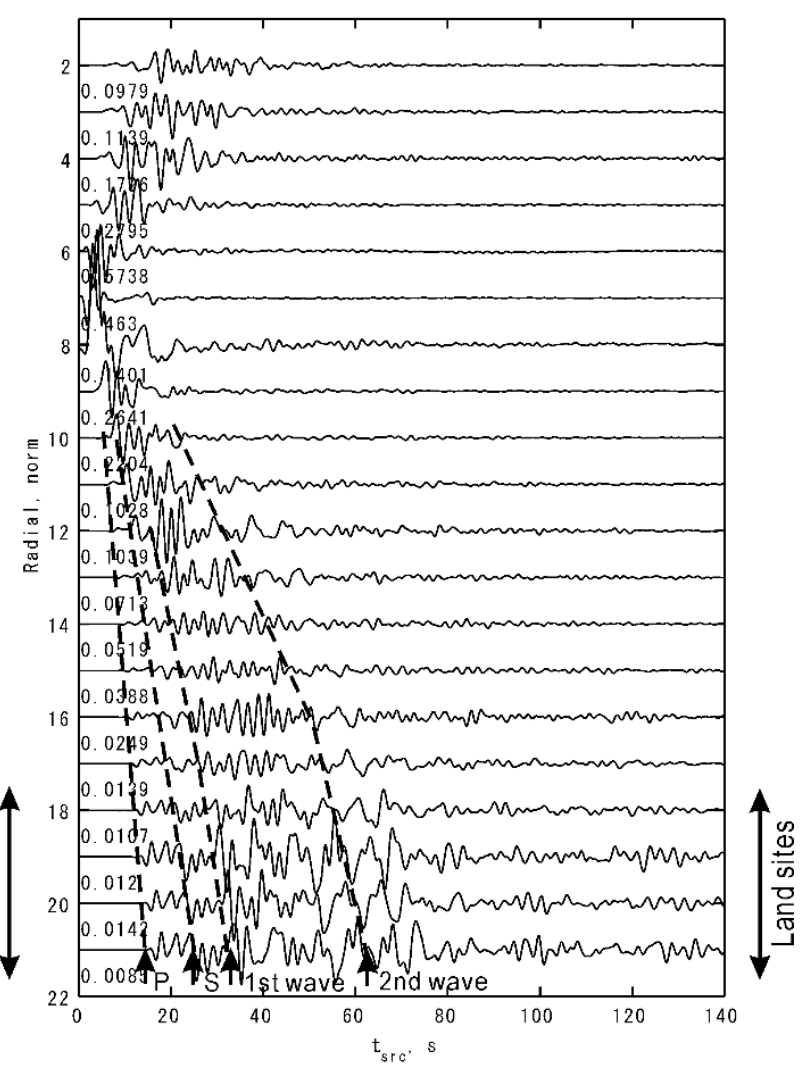

Fig. 5. (a) Simulation results for the source Src1, radial component. Left panel shows the results for the velocity model without water layer, right panel is the same for the model with the water layer. Waveforms for each site are normalized to the peak amplitude of the waveform on the left panel. Numbers are the peak amplitudes of waveforms. (b) Simulation results for the source Src2. (c) Simulation results for the source Src3. 
(c)

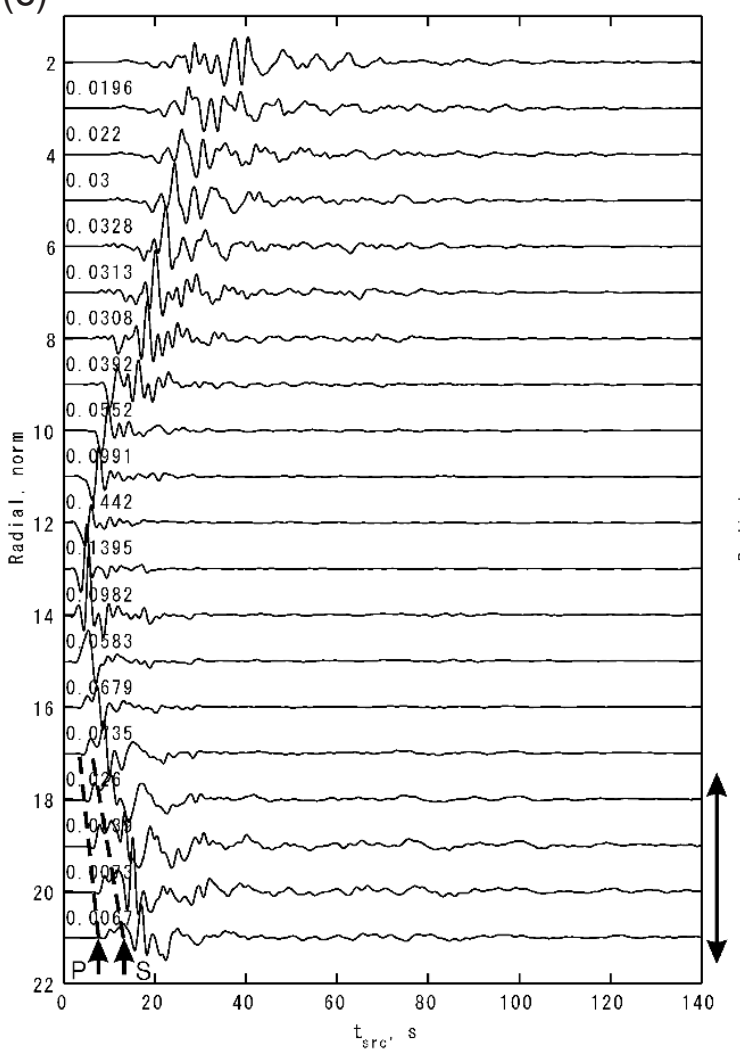

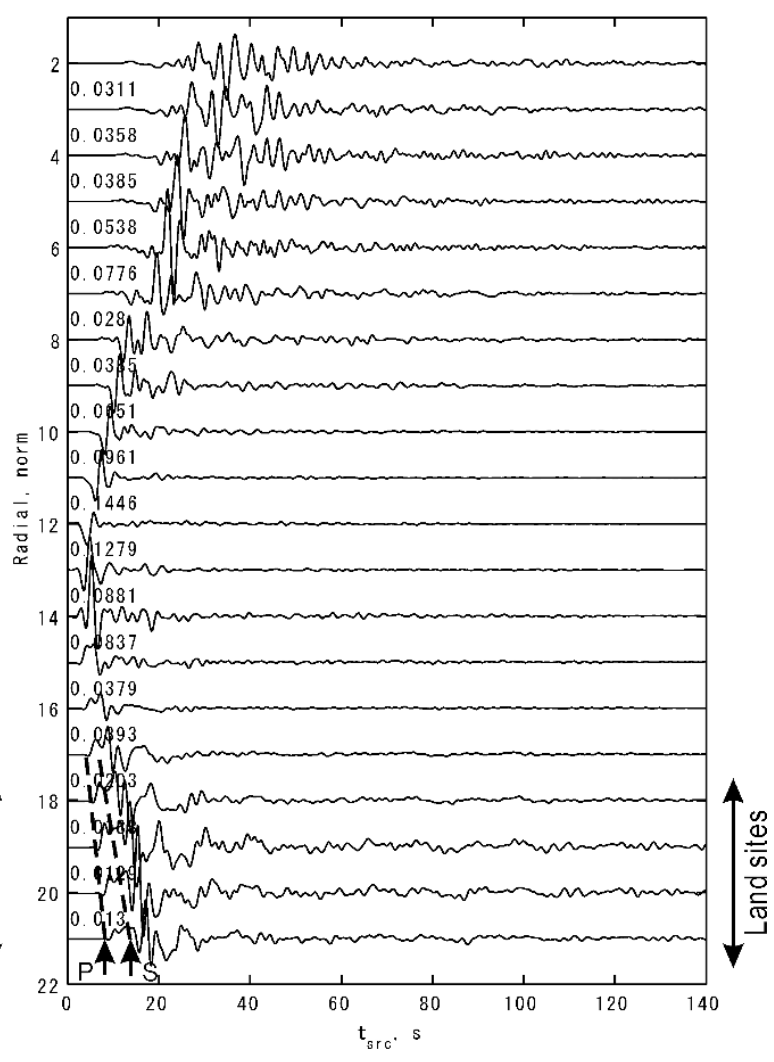

Fig. 5. (continued).

described above, namely, without and with the oceanic water layer, and for the set of sites on the ground surface on a line across the subduction zone directed to the Osaka basin (see Figs. 1 and 4).

High-velocity contrast between low-velocity (OS, LV) and high-velocity (UC, LC, SOC2) layers could result in numerical instabilities. To avoid these, we manually controlled junctions between interfaces and slightly modified them in order to remove sharp wedges. As result, it was possible to run stable calculations from the first attempt. $S$-wave velocity in the water layer should be set to zero. To check if there is a leakage of the $S$-wave into the water layer in this case, we performed a special test. For a simple 1-D velocity model consisting of the ground layer and water layer, we computed ground motions for plane $S$ wave incidence normal to the boundary between layers and found no leakage of plane $S$-wave into the water layer that was caused by modeling or numerical scheme errors.

For the simulations, we employed the 3-D staggered grid finite difference method (Graves, 1996). The shortest target period in the simulations was about $2 \mathrm{~s}$. The smallest shear-wave velocity was assumed to be $1500 \mathrm{~m} / \mathrm{s}$. The finite difference grid size in horizontal directions was $500 \mathrm{~m}$. For depth direction, a non-uniform grid size was used (Pitarka, 1999). For the sedimentary and low-velocity layers shallower than $11,000 \mathrm{~m}$, a grid span was designed to be $125 \mathrm{~m}$; deeper than $11,000 \mathrm{~m}$, the grid span was $250 \mathrm{~m}$. For the calculations, we used 9090 time steps at time intervals of $0.022 \mathrm{~s}$.

The results of the simulations are shown in Fig. 5(a-c) for the radial component. The direct $P$ - and $S$-wave portions have approximately the same amplitudes for the velocity model with oceanic water layer and without water layer. Two groups of surface waves are clearly observed for the shallowest source result. These gradually disappear with increases in the source depth from Src1 to Src3.

\section{Interpretation of Simulation Results}

The most prominent features in Fig. 5(a) and 5(b) are the two surface wave packets. In order to understand their origin, we calculated phase and group velocities from the finite difference simulation results and compared these with the 1-D theoretical phase and group velocity dispersion curves (Saito, 1988), as shown in Fig. 6.

To calculate the group and phase velocities from the finite difference simulation results, we first filtered all simulated waveforms in five frequency bands: $0.01-0.1,0.1-0.2,0.2-$ $0.3,0.3-0.4$, and $0.4-0.5 \mathrm{~Hz}$. Group velocities and phase velocities were then estimated from radial components for each frequency band. Group velocity was calculated as the distance between the first and last site in the selected segment (see Fig. 6, total length of segment is $28 \mathrm{~km}$ ) of the site array divided by the time-delay of the peak of the wavelet packet envelope for the same sites. Phase velocity was calculated as the average ratio of the distance between two adjoining sites $(7 \mathrm{~km})$ and the time-delay of the zero phase of the same wave in the wavelet packet for the same sites. Finally, estimated group and phase velocities were assigned to the central frequencies of waveforms in each frequency band. 

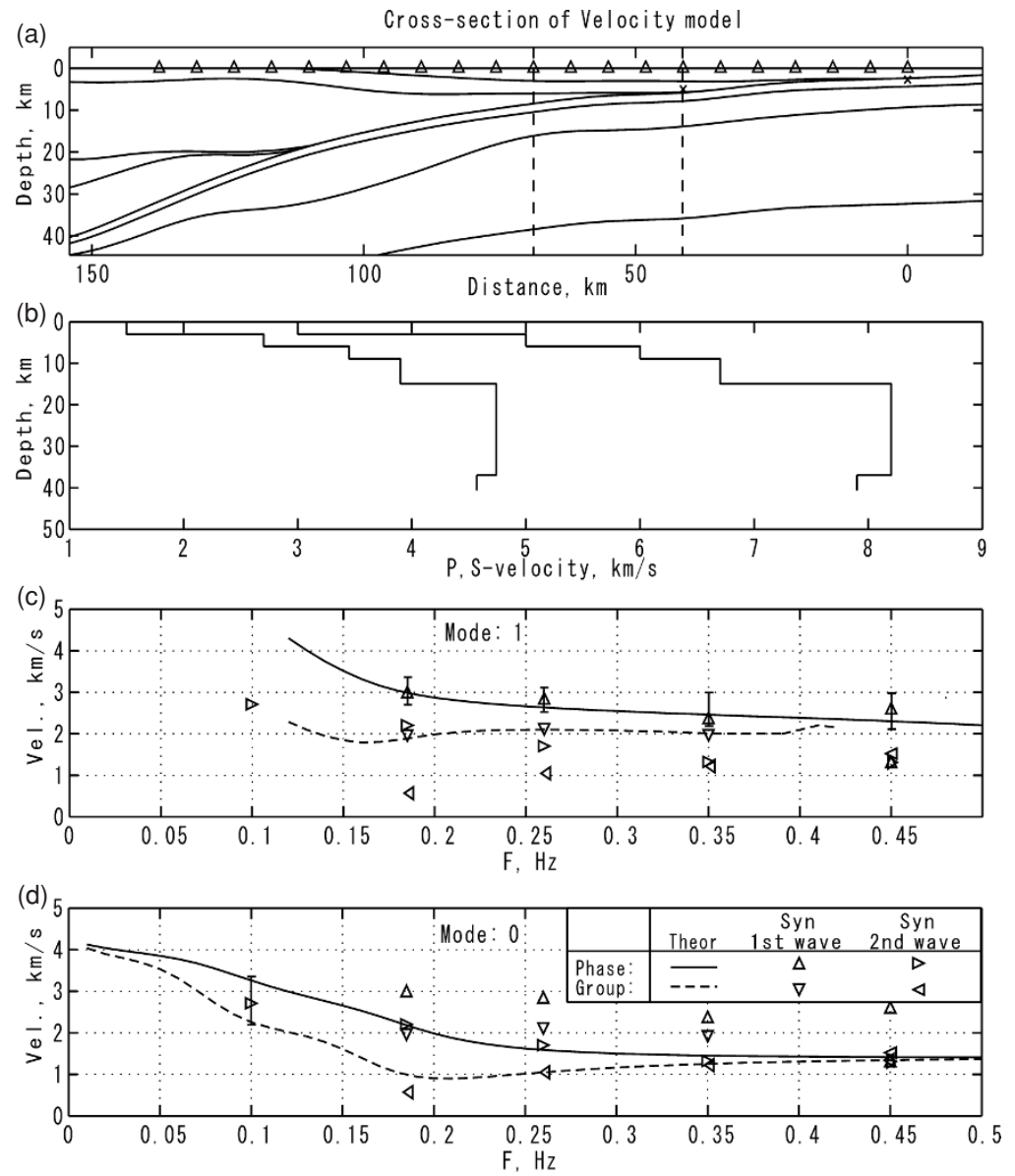

Fig. 6. Analysis of the phase and group velocities. The upper two subplots show the velocity model cross-section and average 1-D velocity model in the target segment of the model bounded by the vertical dashed lines in the upper panel. Lower two panels show phase and group velocities of Rayleigh waves for Mode 1 and Mode 0 (fundamental): theoretical dispersion curves (Saito, 1988) were calculated using the 1-D velocity model above (solid and dashed lines), and velocities were estimated from the simulated waveforms (triangles). Error bars indicate standard deviation of estimates of phase velocities for the first wave packet and for the lowest frequency of the second wave packet. Standard deviations for phase velocities of the second wave packet (as well as standard deviations for group velocities) are much smaller (not shown here in order to maintain the clarity of the picture).

The 1-D velocity model for theoretical calculations was constructed as follows. From the 2-D cross-section of the velocity model without water layer, we selected an approximately horizontal uniform segment (shown between two vertical dashed lines in Fig. 6(a)). For this segment we calculated an average 1-D velocity model, as shown in Fig. 6(b).

Figure 6(d) and 6(c) show comparisons of the results for the Rayleigh fundamental (mode 0) mode and higher (mode 1) mode, respectively. The results clearly show that the second surface wave has phase and group velocities that agree well with the fundamental mode velocities. In contrast, the first surface wave has phase and group velocities that agree with the first higher mode (mode 1) velocities. We should mention that higher modes (mode 1 or mode 2 ) have approximately the same velocities and that their separation within the framework of our study was impossible. For this reason, we use the term "higher mode" without clarifying the number of the mode.

Inland sites, numbers 19-21, were the target sites in our study. In order to compare the simulation results of the velocity model with water layer and without water layer, we compared the maximum amplitudes of waveforms. We found that the amplitudes of direct $S$-waves were the same for both velocity models and for all sources, although they were much smaller than those of the surface waves. With respect to the surface waves, for the shallowest source, Src1, the amplitudes of first wave were similar for both models, while those of the second wave were approximately 1.5 -fold larger for the model without the water layer. For the deeper source, Src2, there was a tendency towards equalization of amplitudes in both models and both surface waves. For the deepest source, Src3, both amplitudes and waveforms themselves became equal. We should mention that the second surface wave that was interpreted as fundamental Rayleigh mode, disappears in the Src3 simulations.

\section{Discussion and Conclusions}

The results of our simulation study show that, in terms of the uncertainties inherent to 3-D velocity modeling, the effect of the water layer is small and can be neglected for relatively deep sources $(>8-10 \mathrm{~km})$. To the contrary, for a shallow source, the error of simulation can be \pm 1.5 -fold, depending on the source location.

Most of the difference arises due to intensive fundamental Rayleigh mode generation in the case of a shallow source 

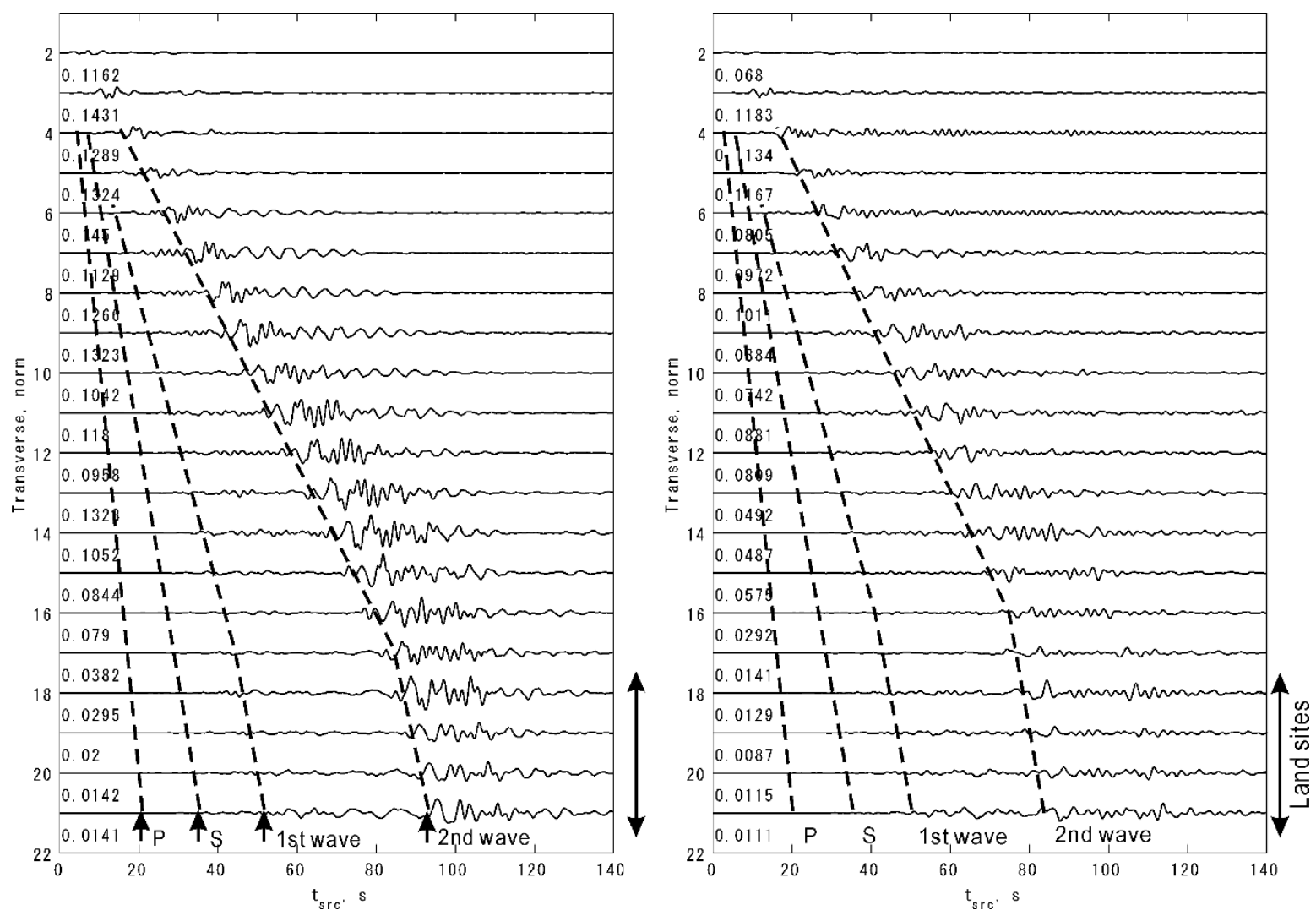

Fig. 7. Simulation results for the source Src1, transverse component. Left panel shows the results for the velocity model without the water layer, and right panel is the same for the model with the water layer. Waveforms for each site are normalized to the peak amplitude of the waveform of the radial component for the model without the water layer (Fig. 5(a)). Numbers are the peak amplitudes of the waveforms.

in the velocity model without a water layer. The velocity model including the water layer strongly suppresses fundamental mode (mode 0 ) generation, likely due to the fundamental mode having its largest amplitude at zero depth, i.e., on the contact surface of ground with the water layer. An additional layer of deep water above this surface suppresses Rayleigh fundamental mode generation. To the contrary, a higher mode has its largest amplitudes at some depth and the water layer has only a small effect. We should also mention that shallow sources easily generate fundamental mode surface waves, while deeper sources generate higher modes.

The effect is strong for Rayleigh waves having a large vertical component, but should be weak for Love waves having no vertical component. In the case of an essentially $3-\mathrm{D}$ velocity model there is a conversion of Rayleigh waves into Love waves, for example on the transversely inclined shallow interface of oceanic sediments. Due to this effect, introducing a water layer also modifies the transverse component (see Fig. 7). $P$ - and $S$-waves avoid the effect of the water layer due to a diving propagation path.

For the model with the water layer, we should consider an interface wave (frequently called Scholte waves; Scholte, 1958) instead of a surface Rayleigh wave. Van Vossen et al. (2002) compared FD simulations with analytical solutions for such waves for two simple cases: (1) with flat water-solid interface and (2) with an inclined interface. These authors recommended using at least 15 grid points per wavelength for the case of an inclined interface to reduce possible errors that increase with increasing dipping angle. Our grid scheme follows this recommendation at periods of maximum amplitudes that are around $3 \mathrm{~s}$. Moreover, due to the smoothness of the model, the maximum dipping angle of the bottom interface is small enough $\left(5^{\circ}\right.$; see, for example, Fig. 3(a) or Fig. 4). A more detailed study was performed by Okamoto and Takenaka (2005) who compared FDM and the discrete wavenumber method (DWM) simulation results. Their recommendations are stricter: 60 grid points per wavelength, and second order staggered grid scheme should be applied in the vicinity of the watersolid interface. We should mention that in most simulation cases, higher amplitudes are obtained for FDM simulations than for DWM simulations. In our case, correction of the calculation method according to the recommendations of Okamoto and Takenaka (2005) could result in slightly smaller amplitudes on Fig. 5(a), right panel.

A comparison of Figs. 1 and 3(d) reveals that in the case of the Nankai and Tonankai earthquake source models by the Central Disaster Prevention Council of Cabinet Office, there are no very shallow asperities that could generate fundamental mode Rayleigh waves. All asperities are deeper than $10 \mathrm{~km}$. However, this model is only one among many hypothetical source models, and in the case of another model having shallower asperity, we need to consider the effect of the oceanic water layer.

To summarize, we conclude:

1. Amplitudes of fundamental mode of Rayleigh waves, which are generated by shallow (around $5 \mathrm{~km}$ in depth) 
sources, are larger for the model without the oceanic water layer than for the model with the oceanic water layer.

2. Amplitudes of higher mode Rayleigh waves are almost the same for both velocity models.

3. Amplitudes of direct $P$ - and $S$-waves are the same for both velocity models.

4. The effect of the water layer can be large and must be considered in the case of a shallow source; it can be neglected in the case of deep sources ( $>10 \mathrm{~km}$ depth).

5. Because all asperities of the expected Nankai and Tonankai earthquake source models are deep, it is possible to neglect the effect of the oceanic water layer on the strong ground motion prediction for these source models.

Acknowledgments. The ideas leading to the finite-difference simulations of the velocity model with water layer were developed during a series of discussions with Ivo Oprsal. Other discussions with Ken Miyakoshi helped to interpret the results presented in this article. The reviews provided by Hiroshi Takenaka and an unknown reviewer were extremely helpful and led to significant improvements in the quality of the manuscript. For the 3-D velocity modeling, we used seismic exploration results from the JAMSTEC and ERI databases and also results of many other studies that we were not able to reference here: we are indebted to all researchers; a full list of references can be found in the DAIDAITOKU-1 report. This study is supported by the 'Regional characterization of the crust in metropolitan areas for prediction of strong ground motion' project 2002-2006 by MEXT, Japan (the DAIDAITOKU-1 project).

\section{References}

ERI database, http://www-es.s.chiba-u.ac.jp/ satot/ERIDB, 2006.

Graves, R. W., Simulating seismic wave propagation in 3D elastic media using staggered-grid finite differences, Bull. Seismol. Soc. Am., 86, 1091-1106, 1996.

Hatayama, K., Theoretical evaluation of effects of sea on seismic ground motion, in Proceedings of the 13th World Conference on Earthquake Engineering, Vancouver, Canada, 2004, paper 3229, 2004.

HERP, http://www.jishin.go.jp/main/index-e.html, 2009.

Ito, K., Crustal seismogenic layer, Chikyu, 38, 114-127, 2002 (in Japanese).

Ito, K., H. Sato, I. Hirose, Y. Umeda, N. Hirata, T. Ito, S. Abe, T. Kawanaka, and T. Ikawa, Crust and upper mantle structure from seismic refraction and wide-angle reflection surveys and its relation to seismic activity in southwest Japan, Eos Trans., 86(52), AGU, Fall Meet. Suppl., Abstract T43A-1364, 2005.

Iwata, T., T. Kagawa, A. Petukhin, and Y. Ohnishi, Basin and crustal velocity structure model for strong ground motion simulation in Kinki area, Japan, J. Seismol., doi:10.1007/s10950-007-9086-7, 2008.

JAMSTEC database, http://www.jamstec.go.jp/jamstec-j/IFREE_center/, 2006.

Kagawa, T., S. Sawada, Y. Iwasaki, and J. Nanjo, Modeling the deep sedimentary structure in the Osaka basin, in Proc. 22nd JSCE Earthquake Engineering Symposium, pp.199-202, 1993 (in Japanese).

Kagawa, T., B. Zhao, K. Miyakoshi, and K. Irikura, Modeling of 3D basin structures for seismic wave simulations based on available information on the target area: case study of the Osaka basin, Bull. Seismol. Soc. Am., 94, 1353-1368, 2004.

Kodaira, S., E. Kurashimo, J. O. Park, N. Takahashi, A. Nakanishi, S. Miura, T. Iwasaki, N. Hirata, K. Ito, and Y. Kaneda, Structural factors controlling the rupture process of a megatrast earthquake at the Nankai trough seismogenic zone, Geophys. J. Int., 149, 815-835, 2002.

Nagano, M. and M. Motosaka, 3-D wave propagation analysis of fluid-soil interaction system using hyperelements for moving loads, in Proceedings of the 9th Japan Earthquake Engineering Symposium, pp. 12911296, 1994 (in Japanese).

Nakanishi, A., H. Shiobara, R. Hino, S. Kodaira, T. Kanazawa, and H. Shimamura, Detailed subduction structure across the eastern Nankai Trough obtained from ocean bottom seismographic profiles, J. Geophys. Res., 103, 27151-27168, 1998.

Nakanishi, A., H. Shiobara, R. Hino, K. Mochizuki, T. Sato, J. Kasahara, N. Takahashi, K. Suyehiro, H. Tokuyama, J. Segawa, M. Shinohara, and H. Shimamura, Deep crustal structure of the eastern Nankai trough and Zenisu ridge by dense airgun-OBS seismic profiling, Mar. Geol., 187, 47-62, 2002a.

Nakanishi, A., N. Takahashi, J. O. Park, S. Miura, S. Kodaira, Y. Kaneda, N. Hirata, T. Iwasaki, and M. Nakamura, Crustal structure across the coseismic rupture zone of the 1944 Tonankai earthquake, the central Nankai Trough seismogenic zone, J. Geophys. Res., 107, 10.1029/2001JB000424, 2002b.

Nakanishi, I., Rayleigh waves guided by sea-trench topography, J. Geophys. Res., 24, 2385-2388, 1992.

Okamoto, T. and H. Takenaka, Fluid-solid boundary implementation in the velocity-stress finite-difference method, Zisin, 57(3), 355-364, 2005 (in Japanese).

Petukhin, A. and T. Kagawa, Methodology for the construction of the 3$\mathrm{D}$ velocity model for the strong ground motion generation in a complex tectonic environment: example of the Philippine subduction zone, Japan, in Proceedings of the First European Conference on Earthquake Engineering and Seismology, Geneva, Switzerland, 3-8 September 2006, Paper Number: 757, 2006.

Petukhin, A., K. Irikura, T. Kagawa, and S. Ohmi, Study of the HF seismic attenuation in Kinki region, Japan, using the ray theory elastic attenuation effect in 3-D velocity model and the 3-D structure of Q-value, in Proceedings of the 13th World Conference on Earthquake Engineering, Vancouver, Canada, paper 633, 2004.

Pitarka, A., 3D elastic finite-difference modeling of seismic motion using staggered grids with nonuniform spacing, Bull. Seismol. Soc. Am., 89, 54-68, 1999.

Saito, M., DISPER80: A subroutine package for the calculation of seismic normal mode solutions, in Seismological Algorithms: Computational Methods and Computer Programs, edited by D. J. Doornbos, pp. 293319, Academic Press, New York, 1988.

Salah, M. K. and D. Zhao, Mapping the crustal thickness in Southwest Japan using Moho reflected waves, Phys. Earth Planet Inter., 141, 7994, 2004.

Scholte, J. G. J., Rayleigh waves in isotropic and anistropic elastic media, Meded. Verhand. KNMI, 72, 9-43, 1958.

Shiomi, K., K. Obara, and H. Sato, Moho depth variation beneath southwestern Japan revealed from the velocity structure based on receiver function inversion, Tectonophysics, 420, 205-221, 2004.

Tsurugi, M., B. Zhao, A. Petukhin, and T. Kagawa, Strong ground motion prediction in Osaka prefecture during the Nankai and Tonankai earthquake, J. Struct. Eng., 51A, 501-512, 2005 (in Japanese).

Van Vossen, R., J. O. A. Robertsson, and C. H. Chapman, Finite-difference modeling of wave propagation in a fluid-solid configuration, Geophysics, 67, 618-624, 2002.

Yamada, N. and T. Iwata, Long-period ground motion simulation in the Kinki area during the $M_{J} 7.1$ foreshock of the 2004 off the Kii peninsula earthquakes, Earth Planets Space, 57, 197-202, 2005.

Yamauchi, M., K. Hirahara, and T. Shibutani, High resolution receiver function imaging of the seismic velocity discontinuities in the crust and the uppermost mantle beneath southwest Japan, Earth Planets Space, 55, 59-64, 2003.

Zhao, D. and A. Hasegawa, P wave tomographic imaging of the crust and upper mantle beneath the Japan islands, J. Geophys. Res., 98(B3), 43334353, 1993.

A. Petukhin (e-mail: anatolyp@geor.or.jp), T. Iwata, and T. Kagawa 